\section{Equitable access to quality education in elementary school mathematics}

\begin{tabular}{|c|c|}
\hline $\begin{array}{l}\text { In a study contrasting an } \\
\text { assessment-heavy approach } \\
\text { that concentrates on 'getting } \\
\text { the answer right' with one that } \\
\text { promotes the development of } \\
\text { mathematical thinking in the } \\
\text { elementary school classroom, } \\
\text { Professor Brian Hudson, from } \\
\text { Karlstad University and the } \\
\text { University of Sussex, examines } \\
\text { what constitutes educational } \\
\text { quality in terms of mathematics } \\
\text { education. This research } \\
\text { demonstrates that in order } \\
\text { to ensure fair and impartial } \\
\text { access to quality education, } \\
\text { epistemic quality is paramount. } \\
\text { Consequently, the goal is to } \\
\text { create curriculum principles that } \\
\text { give all pupils the best possible } \\
\text { chance of accessing a high- } \\
\text { quality mathematics education. }\end{array}$ & $\begin{array}{l}\text { athematics can be viewed as a } \\
\text { 'Iove it or hate it' subject, with } \\
\text { the common notion that some } \\
\text { people can do it and some people can't. } \\
\text { An individual's experience of mathematics } \\
\text { education can provoke a belief of either } \\
\text { being a 'maths person' or not, with the } \\
\text { associated impact on their learning. } \\
\text { Labelling a learner as 'not a maths person' } \\
\text { has been shown to oppress the learner, } \\
\text { supressing their creativity and limiting } \\
\text { their autonomy. } \\
\text { Brian Hudson, Senior Professor in the } \\
\text { Department of Educational Studies at } \\
\text { Karlstad University in Sweden, Emeritus } \\
\text { Professor rat the University of Sussex and } \\
\text { Honorary Professor at the University of } \\
\text { Dundee, examines a variety of approaches } \\
\text { to mathematics education. In a study that } \\
\text { contrasts an assessment-heavy approach, } \\
\text { concentrating on demonstrating } \\
\text { knowledge and 'getting the answer right', } \\
\text { with an approach that promotes the } \\
\text { development of mathematical thinking in } \\
\text { the primary classroom, Professor Hudson } \\
\text { simultaneously addresses the challenges } \\
\text { of the United Nations Sustainable }\end{array}$ \\
\hline
\end{tabular}

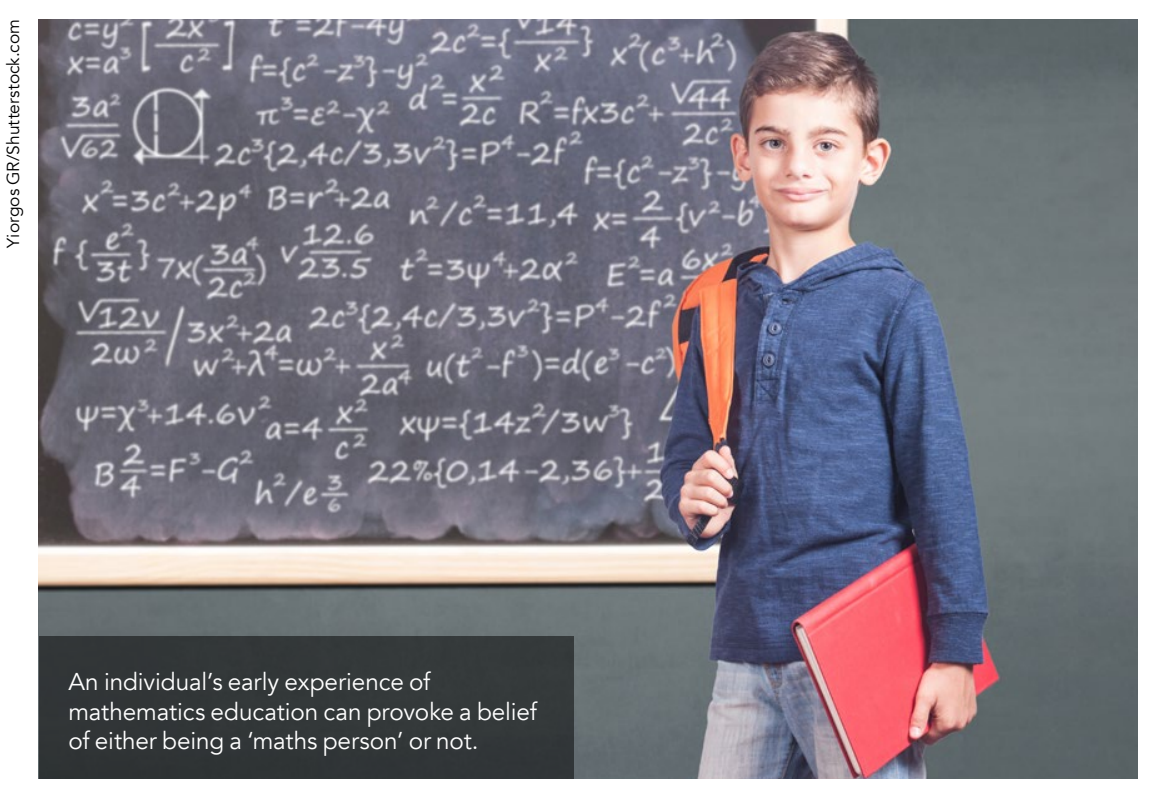

Development Goal 4 (SDG4): 'to ensure inclusive and equitable quality education' for all. SDG4 poses challenges at both global and national levels for societies and their educational systems, particularly in an age of mass migration.

This equitable access to quality education is not simply a question of school enrolment figures are an inatequate indicator of access to education because students enrolled in school are not necessarily in school, and students in school are not necessarily engaged in productive learning. Professor Hudson explains that, "it is necessary that the curriculum be underpinned by the curriculum principle of epistemic access that maximises the chances for all pupils to experience high-quality education in school mathematics."

EPISTEMIC QUALITY Professor Hudson argues that in order to ensure fair and impartial access to quality education, the epistemic (relating to knowledge) qualty of, "what students ble to do in school mathematics" in relation to their mathematical knowledg and skill is paramount This is related to a trajectory in the development of expertise from novice towards becoming an expert in the subject. Consequently, the goal is to create curriculum principles that give all pupils the best possible chance of accessing a high-quality

JONT ACTION TH

JONT ACTION THEORY IN DIDACTICS

The theoretical framework of Joint Action Theory in Didactics (JATD) developed from French didactics (a theory of
teaching), which holds 'learning from teaching), which holds learning from the situation' as a fundamental principle,
influences Professor Hudson's research.

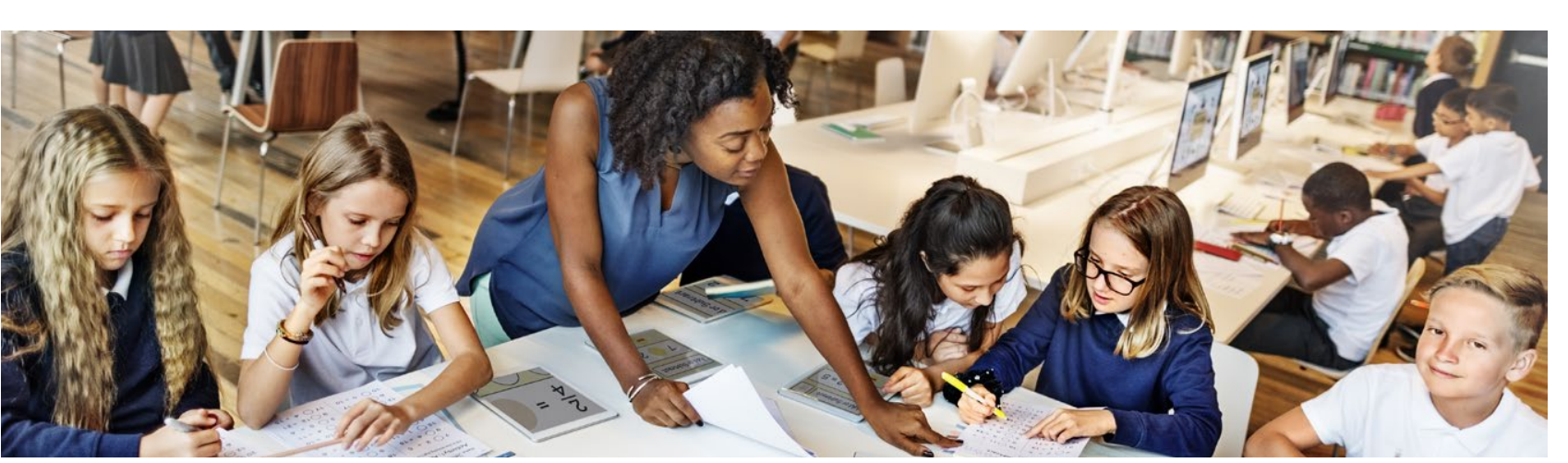

A didactic activity involves someone teaching and someone learning and form part of a didactic system comprising three subsystems: knowledge, the teacher and the student. This didactic triad cannot be separated as it is considered that one cannot grasp the meaning of the teacher's oftion without having an understanding (the of the know' action, and he strictron

\section{PARALLEL STUDIES}

arch questions centre on the quality of the teacherstudents joint action together with the epistemic quality of the knowledge being communicated. This study draws on the research findings of two projects: Developing Mathematical Thinking in the Primary Classroom (DMTPC), which was directed by Professor Hudson and funded by the Scottish Government, and a parallel study examining the assessme practices of mathematics teachers in Chana. Both empirical research proje in elementary schools. The DMTPC project involved a group of in a Masters course created to promote the development of mathematical thinking in the classroom. The cours designed around three key questions:

Example tasks showing active involv

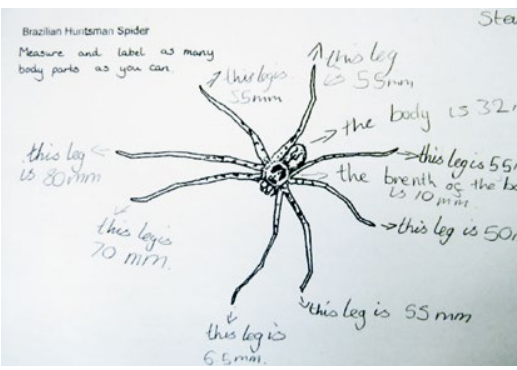

Image 1: Kaye's measurements of the spider
-What is mathematics?

-What is mathematical thinking? -What is good mathematics teaching? Participants also completed an action research project, with their reports signment.

WHAT IS GOOD

MATHEMATICS TEACHING?

Examining what constitutes good

mathematics teaching prompted

expressed their aspirations to 'make a difference' to the mathematics education experienced by their pupils, encouraging them to develop their understanding of both how malhematics works and why mathematics works together with an appreciation of how mathe
than simply right or wrong.

Professor Hudson presents one DMTPC project participant's action research

The goal is to create curriculum principles that give all pupils the best possible chance of accessing a high quality mathematics education.

the teachers to review and contrast their own experiences of mathematics at school. This brought about one of the key findings of the study, emphasising how mathematics can disintegrate from What was envisaged in the curriculum. Vivid memories of 'not the curiculum. 'learning to pass exas' fes' and inteniew responses Furthermore, being labelled according to their performance in the mathematics classroom, together with the stigma that went with it, was prevalent among the participants'

recollections. Consequently, the teachers

project as an exemplary case study demonstrating both high-quality join action between teacher and students and high quality of content in primary school mathematics. This assignmen illostrates accessible and inclusive mathemalics in the classroom that could to high-quality episemic acess for all.

MATHEMATICAL FALLIBILISM AND MATHEMATICAL FUNDAMENTALISM

A discussion of the contrasts between mathematical fallibilism and mathematica
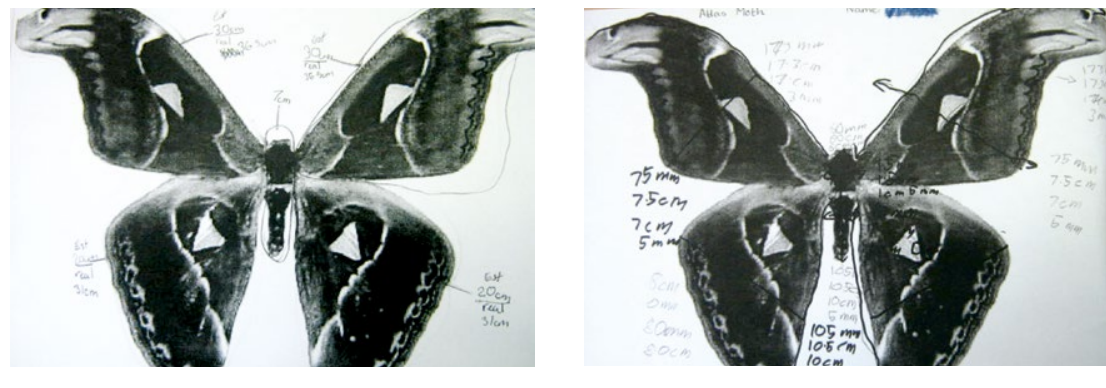

Image 2: Jenny's measurements of the moth 
fundamentalism also highlighted the nature or he mathematics that the fallibilism is based on a histic view of mathematics as a human activity and proposes that this human mathematica activity actually produces mathematics. It involves viewing mathematics as fallible and refutable with an uncertain that promotes critical thinking and creative reasoning, where it is possible to generate multiple solutions and lear from errors and mistakes. Mathematical fundamentalism reflects an authoritarian viewpoint where mathematics is absolutist, irrefutable and infallible. Learners have a fearful and anxiety-inducing experience of mathematics as a subject that is boring and demotivating, involving the following of rules and strict procedures with right from mathematics itself mitigating agan inclusive education.

The counterproductive impact of the mathematical fundamentalism is apparen when one considers the pressures that go with high stakes external testing inspections, summative assessment and school league tables. The impact of assessment practices was highlighted in the Ghana study, which revealed an emphasis on memorising, drill and practice, factors that can exacerbate low epistemic quality.

Professor Hudson argues that assessment for learning that involves low stakes formative and self assessment will promo find this kind of assessment and motivating and can gain enjoyment

a creative human activity.

\section{KNOWING THAT}

This study also stresses the difference between 'knowing that' (propositional knowledge) and 'knowing how' (procedura knowledge). Moreover, Professor Hudson highlights how these terms can describe every aspect of the curniculum. An overemphasis on 'knowing that' is simply

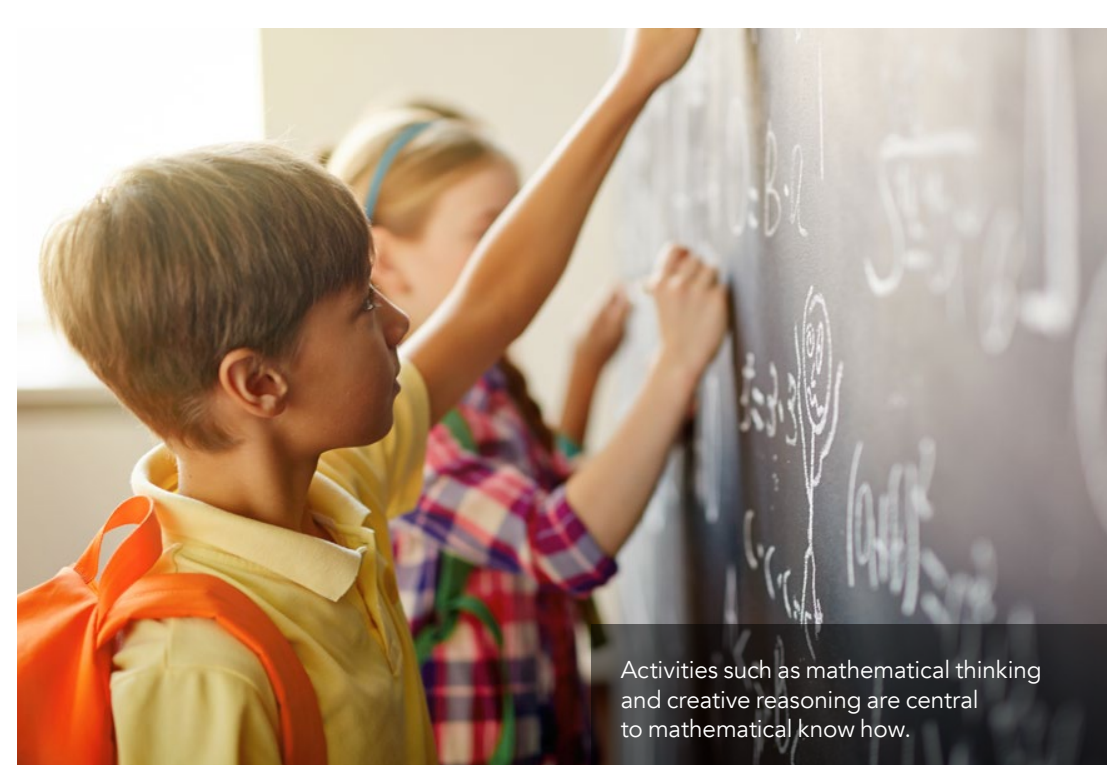

factual knowledge of low epistemic quality, at the University of Helsinki from 16th to where students are taught to know things 'knowing how' involves understanding how the conceptual knowledge coheres therefore eliciting higher epistemic quality. This is a precarious kind of knowledge where students learn how to find out new things through experience. Activities suc as mathematical thinking and creative reasoning are central to mathematica

know how.

\section{DISSEMINATION}

Professor Hudson is a member of the ROSE (Research on Subject-Specific Education) interdisciplinary research gro at Karlstad University, whose members share a focus on subject didactics. The rOSE group joins cross-disciplinary and England to fom the KOSS methork (Knowledge and Ouality across School Subjects and Teacher Education).

Recently, members of the KOSS network were at ECER 2019, the conference for Education in an Era of Risk - the Role of Educational Research for the Future, in Hamburg where they organised a two-p symposium on Epistemic Quality across School Subjects and Teacher Education.

\section{FUTURE PLANS}

recent meeting

Assessment for learning that involves low stakes formative and self assessment will promote high epistemic quality. at the University of Helsinki from 16 th to
18th October 2019 centred on 'Epistemic Quality across School Subjects and Teacher Education' and Professor Hudson paper 'Enistemic Quality for Equitable Access to Quality Education in Schoo Mathematics', which is also the focus of this article.

Professor Hudson's work with the KOSS network has led to discussions with a publisher about two book proposals. - International Perspectives on Powerful Knowledge and Epistemic Quality across School Subjects and

- International Perspectives on Powerful Knowledge and Epistemic Quality: Implications for Innovation in Teach Education Policy and Practice Boh books have a proposed

\section{NATIONAL SIGNIFICANCE}

The significance of this research to the a 'knowledge-rich' or 'knowledgebased" curriculum in England is evident. Professor Hudson warns how this contex knowledge is heavily influenced by the standpoint of the Core Knowledge Foundation. These are resources imported from the USA that are promoted in English schools. They rely heavily on purely factua knowledge i.e. knowing that and have the potential to jeopardise education quality. With his long experience in studying mathematics education, Professor Hudson is convinced that
an emphasis on 'knowing how' is key
for quality learning.

\section{Behind the Research}

\section{Professor Brian Hudson}

E: b.g.hudson@sussex.ac.uk W: http://www.sussex.ac.uk/profiles/210892

\section{Research Objectives}

Prof Hudson's work examines approaches to mathematics the effect of an assessment-heavy approach which emphasises 'getting the answer right' and demonstrating knowledge with an approach which 至phasises the development of an understanding of how as more complex than simply right or wrong.

\section{Detail}

\section{Bio}

Brian Hudson is Senior Professor in the Department of Educational Studies at Karlstad University in Sweden. He is Emeritus Professor and former Head of the School of Education and Social Work (2012-16) at the University of Sussex and also Honorary Professor at the University of Dundee.

Funding Learning Directorate - Scottish Government for supporting the DMTPC project (2010-2012) with a grant of $£ 46,331$.

\section{Collaborators}

Members of the ROSE group - Research on Subjectspecific Education at Karlstad University https://www.kau se/en/rose - in particular professors Christine Olin-Scheller,

Action in Didactics the University of Rentar profssors Monique Loquet at of Trier and the late Meinert Meyer at the University of Hamburg.

- Dr Evelyn Owuso Oduro - former Executive Secretary of the National Teaching Council, Ghana.

- Dr Sheila Henderson and Dr Alison Hudson both formerly at the University of Dundee.

- Also members of the KOSS network funded by the Swedish Research Council (2019-21)

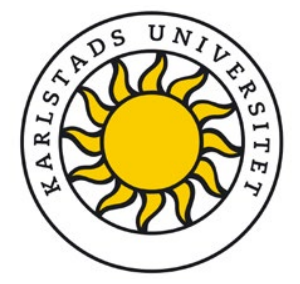

\section{References}

Hudson, B. (2019). Epistemic quality for equitable access to quality education in school mathematics. Journal of to quality education in 1 (4)ool mathen
Curriculum Studies. 51 (4), 437-456.

Hudson, B. (2018). Powerful knowledge and epistemic quality in school mathematics. London Review of Education

Gericke, N., Hudson, B., Olin-Scheller, C., Stolare, M. (2018). Powerful knowledge, transformations and the need for empirical studies across school subjects. London Review of

Hudson, B. (2016). Boredom, alienation and anxiety in the maths classroom? Here's why. The Conversation. Ionline Available at: http://theconversation.com/boredomalienation-and-anxiety-in-the-maths-classroom-heres

Hudson, B., Henderson, S., Hudson, A. (2015). Developing students and teachers as learners of mathematics. Journal of Curriculum Studies, 47 (3), 374-398.

Hudson, B., Henderson, S., Hudson, A. (2012). Developing Mathematical Thinking in the Primary
Project. 10.13140/RG.2.1.1396.0729.

\section{Personal Response}

What advice would you give to government education departments to help then develop equitable access to quality mathematics education?

II Policy makers need to recognise that it is at the classroom level that curriculum and pedagogy effectively merge. It is not the role of government departments to import commercial curriculum resources from the government needs to ensure systems of support for teachers as 'curriculum makers' who, through their own professional development and networking, ensure equitable access to quality education for all. In the case of mathematiss teaching the emphasis should be on the such as mathematical thinking, problem solving and creative reasoning. 